\title{
Precipitating causes of acid reflux episodes in ambulant patients with gastro-oesophageal reflux disease
}

\author{
C P Barham, D C Gotley, A Mills, D Alderson
}

\begin{abstract}
Previous studies of the mechanisms that precipitate acid reflux episodes have used short term hospital based measurements. A 24 hour $\mathrm{pH}$ and motility recording system, incorporating a sphincter monitoring device, has been developed to study naturally occurring acid reflux episodes in control subjects and patient groups with different grades of oesophagitis. Lower oesophageal sphincter relaxations related to episodes of acid reflux were common in control subjects $(67 \%$ of episodes) but became more difficult to detect as the grade of oesophagitis increased (grade 0/1 $-67 \%$, grade $2 / 3-35 \%$, grade $4-13 \%$ ). A variety of events that produced recognisable transdiaphragmatic pressure patterns were associated with acid reflux episodes. In control subjects $74 \%$ of acid reflux episodes were precipitated by belching but this mechanism became less evident as the grade of oesophagitis increased (grade $0 / 1-43 \%$, grade $2 / 3-40 \%$, grade $4-29 \%$ ). Activities that produced a pressure gradient across the diaphragm became increasingly important as events precipitating acid reflux as oesophagitis became more severe (controls - 2\%, grade 0/1 - 15\%, grade $2 / 3-11 \%$, grade $4-22 \%$ ). This study has shown the pressure events surrounding acid reflux in fully ambulant patients with gastro-oesophageal reflux disease. (Gut 1995; 36: 505-510)
\end{abstract}

Keywords: acid reflux, gastro-oesophageal reflux disease.

Previous studies on the mechanisms responsible for precipitating acid reflux episodes show that the lower oesophageal sphincter (LOS) plays a key part. Patients with oesophagitis have a decreased resting LOS pressure when compared with control subjects ${ }^{1}$ and an absent sphincter pressure may be the cause of acid reflux in some patients. ${ }^{2}$ Transient relaxations of the lower oesophageal sphincter have also been found during almost all reflux episodes in control subjects ${ }^{3}$ and in most episodes in patients with reflux oesophagitis. ${ }^{4}$ These relaxations were found to be neurally mediated and an abnormality of the belch reflex has been postulated as their cause. ${ }^{5}$ Transdiaphragmatic stress activities such as straining, straight leg raising, and abdominal compression have also been shown to precipitate acid reflux episodes. ${ }^{67}$
Most of these studies have used water perfused manometry equipment that constrains subjects to a supine immobile position. Clearly the results of these unphysiological studies may not correctly reflect what actually occurs during normal daily activities nor accurately show the comparative importance of the various events that lead to acid reflux.

To study the mechanisms precipitating acid reflux episodes in fully ambulant patients with gastro-oesophageal reflux disease (GORD) a unique 24 hour recording system was developed that incorporates oesophageal $\mathrm{pH}$ measurement and simultaneous oesophageal body and gastric pressure recordings combined with assessment of LOS function.

\section{Methods}

SUBJECTS

Eighteen healthy volunteers (12 men) with a median age of 48 years (interquartile (IQ) range 28-61) were compared with three groups of patients with GORD. Control subjects had no symptoms of GORD or peptic ulceration, had not had gastric or oesophageal surgery, and were not receiving drugs known to affect gastrointestinal motility. The 49 patients had reflux symptoms for greater than six months and had an abnormal 24 hour $\mathrm{pH}$ study or the presence of oesophagitis on endoscopic examination, or both, as defined and graded using the Savary Miller system. ${ }^{8}$ Twenty patients had mild disease (grades $0 / 1$, age 57 IQ range $45-66,14$ men), 15 patients had erosive oesophagitis (grades $2 / 3$, age 54 IQ range $49-65,11 \mathrm{men}$ ), and 14 patients had oesophageal strictures (grade 4, age $67 \mathrm{IQ}$ range 58-73, nine men). Informed consent was obtained from each subject and the investigation was approved by the local ethical committee.

\section{RECORDING EQUIPMENT}

Twenty four hour measurements were made using a combined $\mathrm{pH}$ and manometry system as described in detail in previous reports. ${ }^{9}{ }^{10} \mathrm{It}$ essentially consists of two connected catheters, one measuring $\mathrm{pH} 5 \mathrm{~cm}$ above the LOS $(2.1 \mathrm{~mm}$ diameter antimony $\mathrm{pH}$ electrode, Synectics, Sweden) and the other measuring pressures at several sites. The solid state manometry catheter (CTO-5/Sphinctometer, Gaeltec Ltd, Isle of Skye, Scotland) contains three oesophageal body transducers, a $6 \mathrm{~cm}$ long oil filled sphincter monitoring device, ${ }^{11}$ 


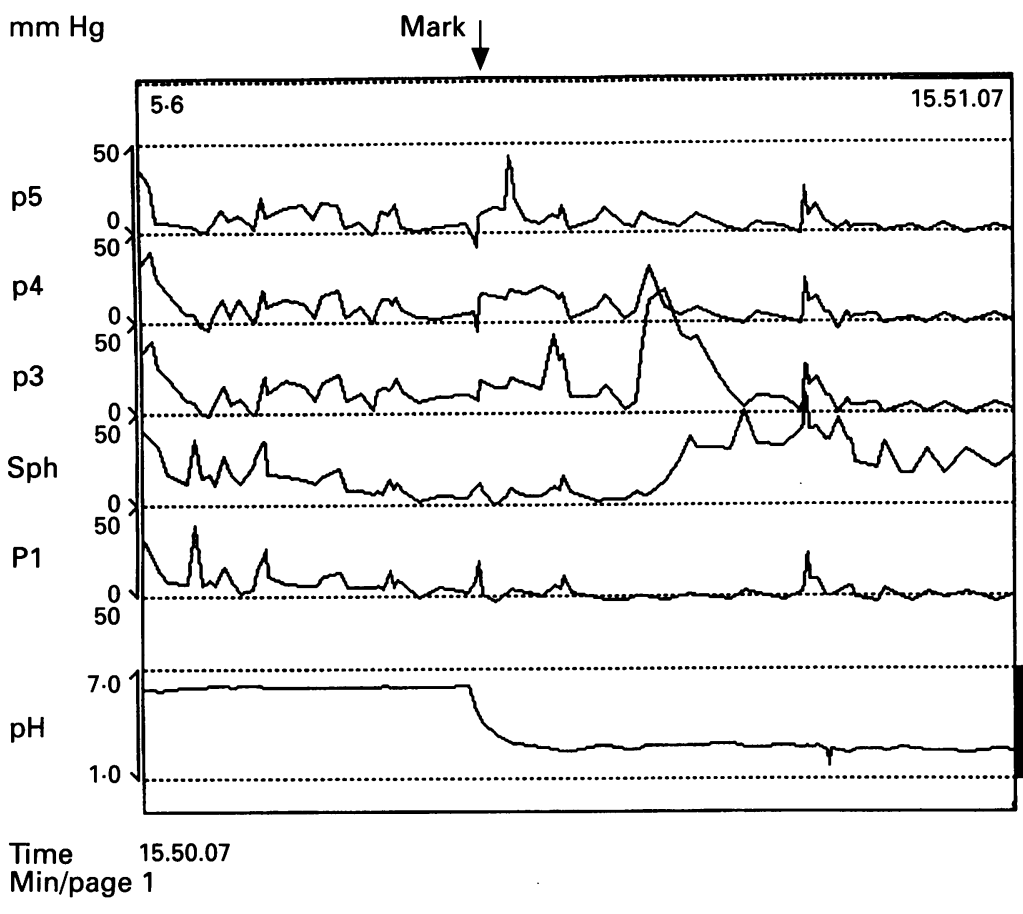

Figure 1: An acid reflux episode occurring during a lower oesophageal sphincter relaxation $(S p h=L O S)$. Reflux episode followed a belch (marked by arrow).

and a gastric pressure transducer all housed in a $2.5 \mathrm{~mm}$ diameter steel braided, silicone coated catheter. Both catheters are connected to a 24 hour recording unit (7-MPR, Gaeltec Ltd), which contains a microprocessor for data compression. At the completion of the study, data are downloaded on to a desktop computer for further analysis using an automated analysis program.

\section{STUDY PROTOCOL}

Subjects were studied after an overnight fast and after the withdrawal of all drugs likely to influence gastric secretion, $\mathrm{pH}$, or gastrointestinal motility for 48 hours. The $\mathrm{pH}$ and pressure catheters were calibrated, tied together, and passed through the nose (anaesthetised with $1 \%$ lignocaine spray, Astra Pharmaceuticals, Hertfordshire) into the stomach. A standard motility test was carried out, with the patient in the sitting position, by withdrawing the catheter in $1 \mathrm{~cm}$ increments to establish the position and resting pressure of the LOS. Catheters were then secured so that the $\mathrm{pH}$ and the lowest oesophageal pressure transducer were $5 \mathrm{~cm}$ above the previously determined LOS. For the 24 hour study, patients were instructed to carry out normal daily activities; record meals, drinks, position, activities, and symptoms on a diary sheet; and to use the event button.

\section{DATA ANALYSIS}

\section{pH data}

The 24 hour ambulatory recordings were examined manually at each acid reflux episode to identify the precipitating mechanism. An acid reflux episode was considered to begin if oesophageal $\mathrm{pH}$ fell below $4 \cdot 0$ for more than five seconds and ended when the $\mathrm{pH}$ rose above $5 \cdot 0$. Standard descriptions of $\mathrm{pH}$ data included the percentage of the recording time that there was acid in the oesophagus (\% time $\mathrm{pH}<4$ ), the number of reflux episodes, and the length of individual acid reflux episodes.

\section{LOS relaxation}

A relaxation of the LOS was determined if the sphinctometer reading showed an obvious reduction in its baseline in the 30 seconds before and maintained beyond the onset of an acid reflux episode (Fig 1).

\section{Mechanisms of acid reflux}

We have previously classified a variety of pressure events associated with episodes of acid reflux in healthy control subjects, ${ }^{10}$ and confirmed their presence under laboratory conditions (Fig 2). Reflux episodes were classified as belch induced, stress related (if caused by activities producing a pressure gradient across the diaphragm such as straining, sniffing, and coughing), and motor related if preceded in the 15 seconds before a $\mathrm{pH}$ fall by an oesophageal body contraction (peristaltic or otherwise). If no pressure activity could be determined before the $\mathrm{pH}$ fall then the acid reflux episode was classified as spontaneous.

Finally, if two or more of the above activities occurred, so that the precipitating cause of the reflux episode could not be confidently determined, the reflux episode was classified as unclear.

\section{STATISTICS}

It was assumed that data were not normally distributed and these are expressed as medians and interquartile ranges (IQ). The MannWhitney U test was used to establish statistical significance.

\section{Results}

\section{pH DATA}

The Table shows the median percentage of the recording time that the oesophageal $\mathrm{pH}$ remained below 4 , the total number of acid reflux episodes, and other conventional measures of acid reflux. Control subjects had less time with acid in their oesophagus (\% time $\mathrm{pH}<4$ ), fewer acid reflux episodes, and acid reflux episodes of shorter duration than all the patient groups. While there were differences between the patient groups the only significant finding was that patients with mild disease (grades 0/1) had fewer acid reflux episodes than patients with erosive oesophagitis (grades $2 / 3)$.

\section{LOS RELAXATIONS}

Figure 3 shows the percentage of acid reflux episodes where a LOS relaxation could be 

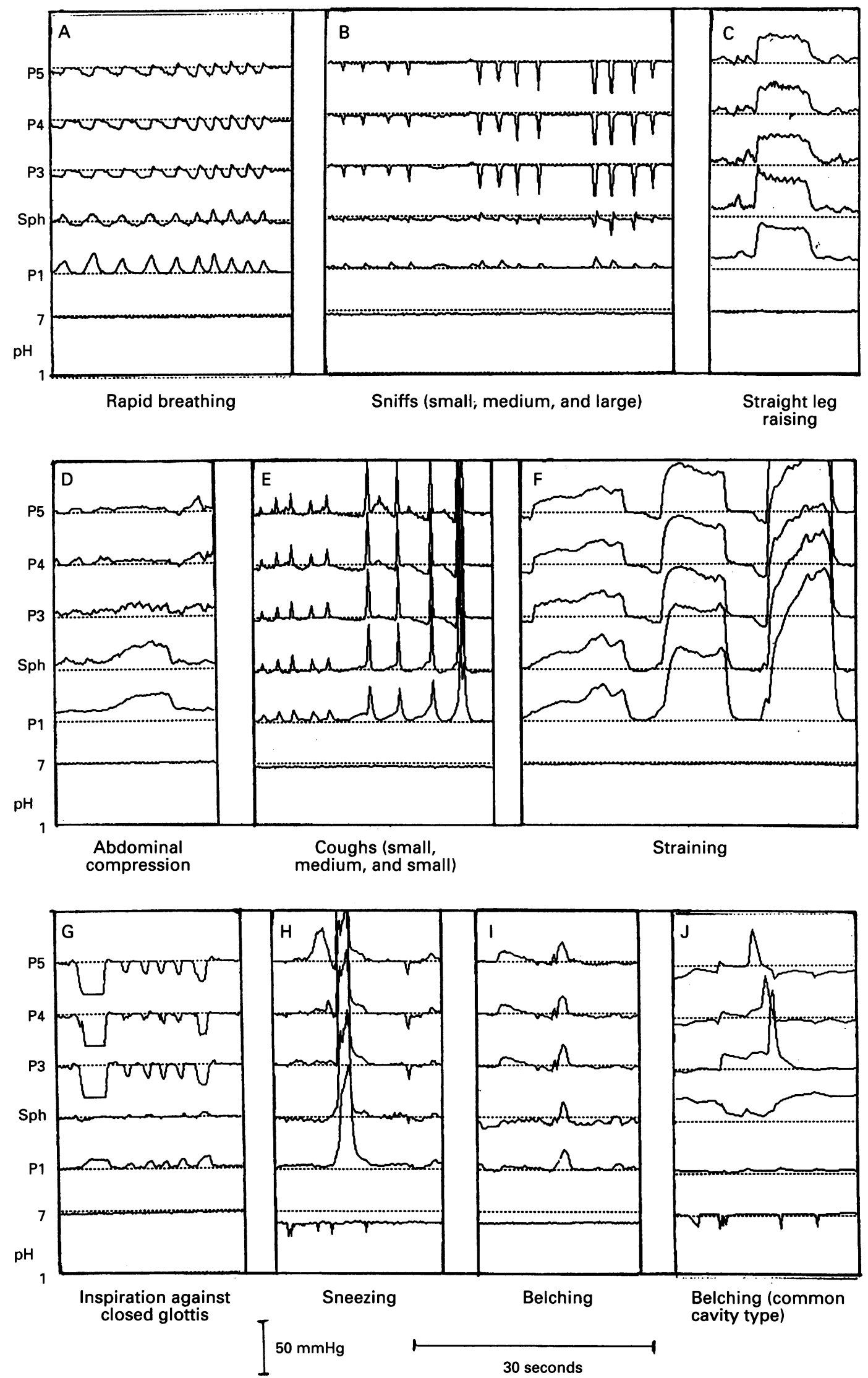

Figure 2: Pressure patterns associated with different physical activities. P5-P3=oesophageal pressure transducers, $S p h=$ sphinctometer, $P 1=$ gastric pressure transducer, $p H=$ lower oesophageal $p H$.

recognised at its onset. There was a similar proportion of acid reflux episodes associated with LOS relaxation in control subjects and patients with mild disease $(67 \%)$. Thereafter there were fewer acid reflux episodes associated with LOS relaxation as the severity of the oesophagitis increased. In episodes where no
LOS relaxation could be determined the reason was that either no reduction in pressure was visible or that sphincter pressure change was hidden by other pressure changes such as coughing, straining or deep breathing. It was unusual, however, for a relaxation to be hidden by pressure artefact. In the vast majority of 
Standard measures of acid reflux over a 24 hour ambulatory study

\begin{tabular}{lcccc}
\hline & Controls & Grade 0/1 & Grade 2/3 & Grade 4 \\
\hline \% Time $\mathrm{pH}<4 \cdot 0$ & $0 \cdot 9(0 \cdot 2-1 \cdot 5)$ & $6 \cdot 2(3 \cdot 9-9 \cdot 1)$ & $10 \cdot 5(5 \cdot 1-17 \cdot 4)$ & $9 \cdot 0(4 \cdot 9-13 \cdot 8)$ \\
Mean number of episodes & $8(5-18)$ & $24(14-35)^{\star}$ & $44(25-63) \dagger$ & $32(21-40)$ \\
Length of episodes (second) & $118(82-156)$ & $321(203-491)$ & $332(246-457)$ & $390(223-495)$ \\
\hline
\end{tabular}

Medians and interquartile ranges. For each of the standard measures: controls $v$ all patient groups $\mathrm{p}<0 \cdot 001 .^{\star} v \dagger \mathrm{p}<0 \cdot 05$.

acid reflux episodes in patients, and especially in those with severe grades of oesophagitis, no LOS relaxation was detected.

\section{PRECIPITATING PRESSURE EVENTS OF ACID REFLUX}

Figure 4 shows the percentages of the different activities associated with, and precipitating, acid reflux episodes. The most striking feature was that, in control subjects, almost all reflux episodes were caused by belching. In patients with GORD, belching remained an important but decreasing cause of reflux episodes as the grade of oesophagitis worsened. In contrast, spontaneous reflux episodes were very rare in control subjects but assumed increasing importance in patients with oesophagitis. In patients with erosive oesophagitis and in those with an oesophageal stricture, a similar proportion of their reflux episodes was caused by spontaneous episodes. Stress induced acid reflux (coughing, sniffing, and straining) was significantly greater in patients than in control subjects with oesophageal stricture patients having the highest values. Reflux episodes preceded by oesophageal motor contractions tended to become more common as the severity of the oesophagitis increased. Reflux episodes preceded by oesophageal motor contractions were very rare in control subjects but accounted for between $4 \cdot 5-10.5 \%$ of episodes in patients. For some reflux episodes, the precipitating cause was unclear as two or more of the above mechanisms occurred simultaneously. While unclear acid reflux episodes seemed to become less common with increasing severity of oesophagitis, differences

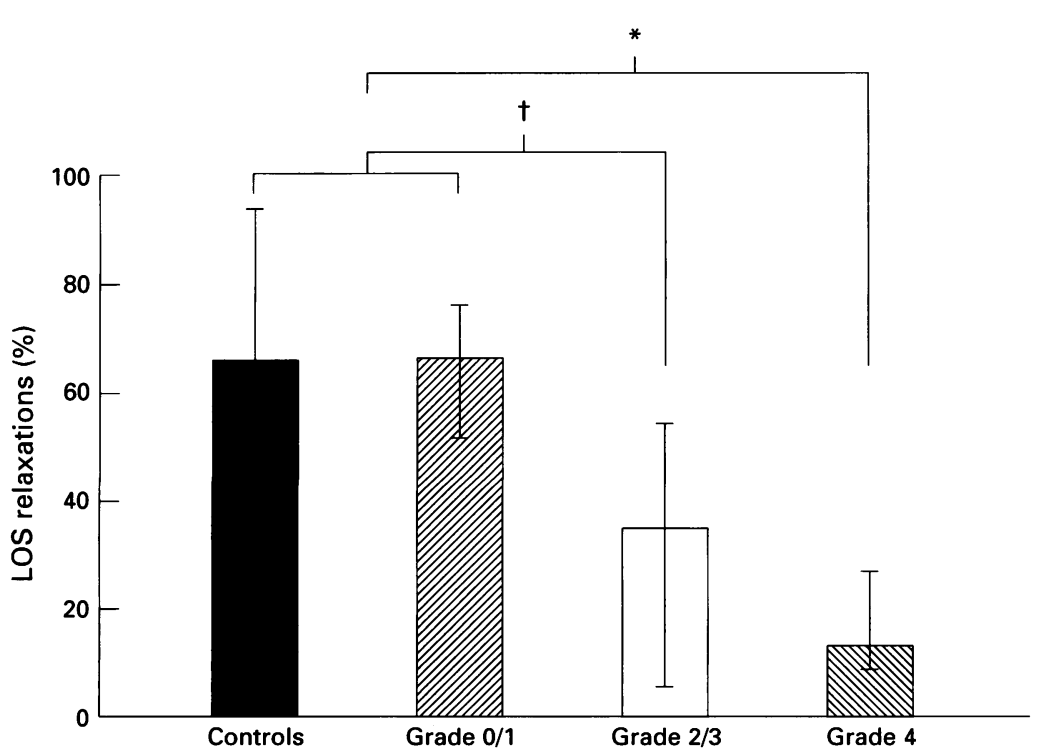

Figure 3: Median percentage of reflux episodes with a visible lower oesophageal relaxation for the subject groups. ${ }^{\star} p<0.001,+p<0.01$. between subject groups were not significant.

\section{Discussion}

This study has examined, for the first time, the precipitating causes of naturally occurring acid reflux episodes in ambulant patients with gastro-oesophageal reflux disease. The $\mathrm{pH}$ data are similar to those reported in other studies where the $\mathrm{pH}$ probe has been positioned manometrically. ${ }^{12-14}$ Ambulatory manometry has shown two important features regarding LOS behaviour around reflux events. Firstly, transient lower oesophageal sphincter relaxations are not as easily recognised during ambulatory studies as in the motility laboratory and, secondly, a number of physiological events, which are not easily recognised in the motility laboratory are readily shown by ambulatory studies.

In previous studies, the Dent sleeve has given detailed information about LOS behaviour around acid reflux episodes, implying that transient LOS relaxations are the most important events precipitating acid reflux in both control subjects and, by occurring inappropriately, also in patients with GORD. Even in patients with a very low sphincter pressure ( $3 \mathrm{~mm} \mathrm{Hg}$ ) a sphincter relaxation was reported before some reflux episodes. Ambulatory studies with the sphinctometer have not been able to show the same detailed information as that obtained using a Dent sleeve, such as the magnitude of the sphincter relaxation, ${ }^{4}$ relaxations of very low basal sphincter pressures or resting LOS pressure over long periods. ${ }^{15}$ This is partly accounted for by the integrating nature of its length/pressure measurement. In addition, non-sphincter related pressure artefact(s), producing pressure changes on both sides of the LOS (normal respiration, exercise, talking, coughing, etc), will mask subtle sphincter pressure changes. The Dent sleeve would also be susceptible to these pressure artefacts in the ambulatory situation but, as all studies with that device have been in supine, immobile subjects, these normal pressure inducing activities are minimised. If the Dent sleeve could be used in an ambulatory situation, very small LOS pressure changes would be difficult to identify, as normal ambulatory respiratory pressure fluctuations can have a magnitude of greater than $20 \mathrm{~mm} \mathrm{Hg}$. In this study, only obvious pressure drops from a baseline reading, at the moment of a reflux episode, were labelled as an LOS relaxation and no other comment was attempted on more complicated LOS motor patterns. Despite this, an LOS relaxation at the moment of reflux was seen during most reflux episodes $(67 \%)$ in control subjects but became more difficult to recognise as the severity of the oesophagitis 


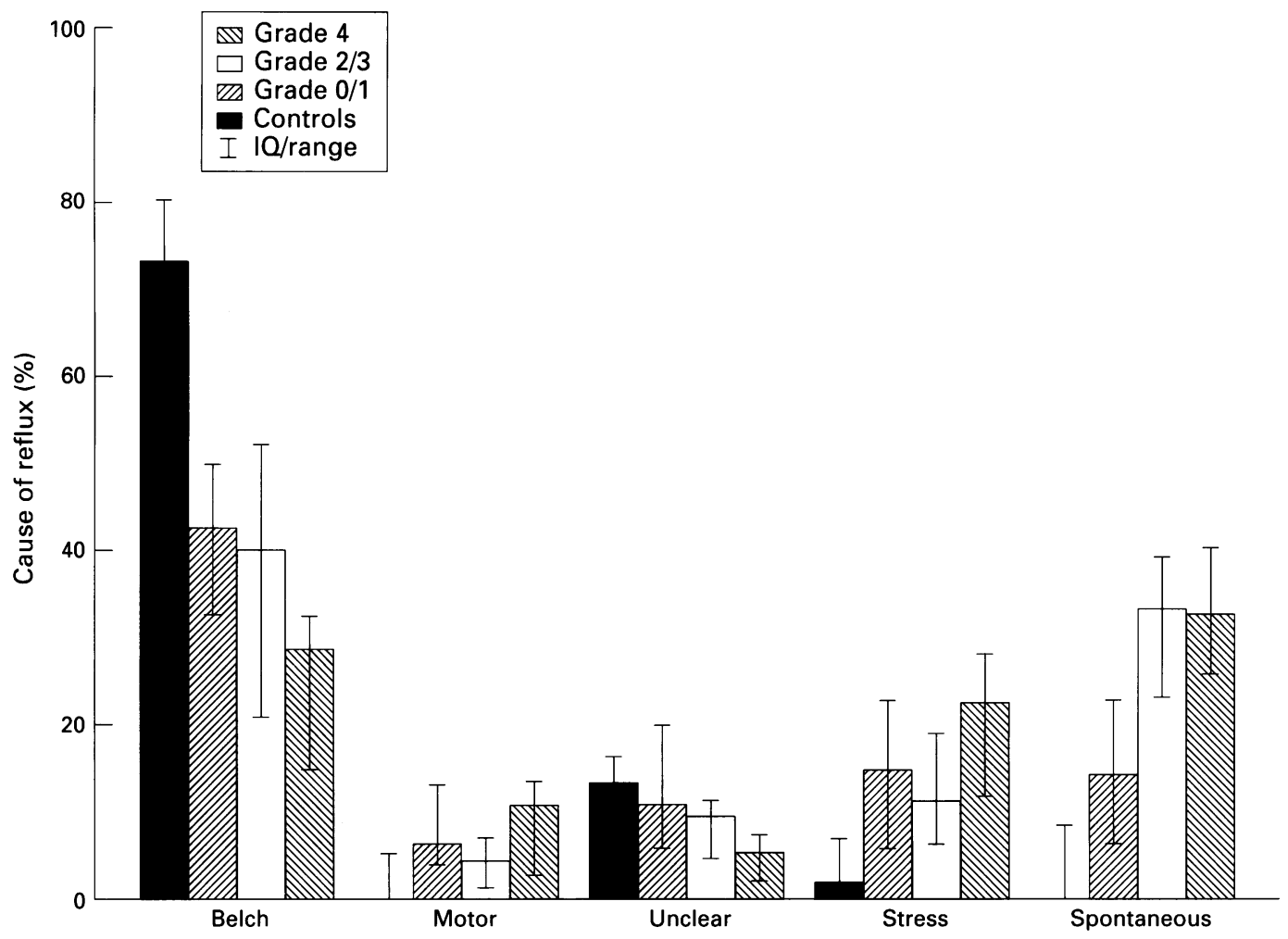

Figure 4: Median percentage of acid reflux precipitating pressure events among the subject groups. (Belch $-C \mathrm{v} 0 / 1,2 / 3,4$ $p<0.001 ; 0 / 1$ v $4 p<0.01$ ), (Motor $-C$ v 0/1, $4 p<0.05 ; 2 / 3$ v $4 p<0.025$ ), (Stress $-C$ v 0/1, 2/3 $p<0.01 ; C$ v 4 $p<0.001)$, (Spontaneous $-C \mathrm{v} 0 / 1 p<0.01 ; C \mathrm{v} 2 / 3,4 p<0.001 ; 0 / 1 \mathrm{v} 2 / 3,4 p<0.001)$.

increased. This is almost certainly a reflection of a decreasing basal LOS pressure in patients with more severe grades of oesophagitis as noted in previous studies. ${ }^{14} 16$ With a low or non-existent sphincter pressure, a relaxation of that pressure would not, for the reasons mentioned above, be detected by the sphinctometer. It is interesting to note that in Fig 1 the LOS seems to relax before the belch. If the desire to belch is neurally mediated by gastric receptors then this might be expected. LOS pressure would need to fall (relax) first before gas would be expelled.

Of more interest, and not mentioned in detail in previous publications, are the pressure events associated with acid reflux episodes in ambulant subjects. This has only been possible because of the combined $\mathrm{pH}$ and motility recording equipment that importantly measures pressures on both sides of the diaphragm. Figure 2 shows a variety of test manoeuvres performed under laboratory conditions and their effects on the pressure traces. Coughing and sneezing produce large but short positive deflections on either side of the diaphragm while straining produces large and longlasting positive pressure deflections. Sniffing (and hiccuping) results in a short lived negative deflection in the oesophageal (thoracic) pressure transducers, with a positive deflection in the gastric (abdominal) transducer. Belching produces two types of pressure patterns. A forceful belch with the gas passing the upper oesophageal sphincter results in a small upward pressure deflection on both sides of the diaphragm. A less forceful belch, against an initially closed upper oesophageal sphincter, results in a common cavity phenomena shown in Fig $2(J)$. The presence of transducers either side of the diaphragm permits the separation of pressure artefact from genuine oesophageal motor activity and also helps determine the nature of the pressure event. For example, a short, weak cough may be indistinguishable from a simultaneous oesophageal contraction when oesophageal pressure transducers only are present in the catheter. The existence of the gastric pressure transducer showing the same type of pressure rise indicates that it must be a cough rather than an oesophageal contraction. The consequent proper classification of these events related to acid reflux episodes in ambulant subjects sheds new light on the usual causes of these episodes.

Belching was the most important cause of acid reflux in control subjects and remained an important (if decreasing) cause in patients with GORD. Belching as a cause of reflux has never featured prominently in previous studies, probably because it is not common in recumbent subjects. The only time that belching occurred in previous studies was when excessive quantities of gas were instilled into the stomach in an effort to produce gastric distension. ${ }^{517}$ Consequently, its importance as a primary mechanism of acid reflux has been underestimated. Despite this, previous studies have noted that some acid reflux episodes were accompanied by belching. ${ }^{14}$ Dent et al showed that most acid reflux episodes were associated with an identifiable common cavity phenomenon and, in addition, some common cavity phenomena occurred without an observable pH decrease, especially after meals (that is, belching) ${ }^{3}$ Finally, transient LOS relaxations associated with acid reflux are virtually identical in pattern to those associated with gastro-oesophageal reflux of gas, ${ }^{5}$ and in one 
study in dogs, $58 \%$ of reflux episodes were accompanied by audible belching. ${ }^{18}$

The activity of belching, however, as 'the' event associated with physiological reflux, has generally not been grasped. Belching is a physiological mechanism to vent ingested gas and is consequently most common in the early postprandial period. This would explain the common finding that most acid reflux episodes occur postprandially when acid inadvertently accompanies the belched gas from a stomach full of gas, food, and acid. How then can these results be equated with the findings of previous studies showing the prime importance of transient LOS relaxations in the cause of acid reflux episodes? It may be that belching occurs because sensory receptors in the gastric fundus, detecting an excessive amount of stomach gas, cause the lower oesophageal sphincter to relax. In any event, reflux of gastric contents, except during 'stress' pressure events, has to occur through a relaxed or nonexistent sphincter. It may be that in the supine position, when belching rarely occurs, transient LOS relaxation is the only mechanism detected by the Dent sleeve associated with acid reflux. Thus, transient LOS relaxations may not be inappropriate at all but might be the mechanism to permit the venting of excessive ingested gas. The reason why it assumes an important role in the cause of acid reflux episodes may be tied into other factors such as the presence of a hiatus hernia (which, if large, and containing gas that is usually in the gastric fundus, may stimulate more belching episodes), a weaker than normal lower oesophageal sphincter, and the excessive saliva swallowing (accompanied by some air) all of which occur in GORD patients. ${ }^{19}$ These hypotheses need further evaluation. Of course, the presence of a catheter in the oesophagus is an irritating stimulus and as such provokes more swallowing. Extra swallows will result in more air ingestion and potentially more belching. Most of this excessive swallowing, however, occurs in the first few hours of a study and tends to decrease as tolerance to the catheter develops. The catheter assembly used in this study does not seem to increase the frequency of reflux events since the $\mathrm{pH}$ data are comparable with other ambulatory studies for control subjects and patients with GORD. Stress induced acid reflux was more important in patients with acid reflux disease than control subjects and this reflects a reduced ability of a low LOS pressure to prevent the pressure challenges of normal daily activities. Spontaneous acid reflux became more common with increasing severity of oesophagitis. Patients with erosive oesophagitis and those with strictures were found to have a similar number of spontaneously induced acid reflux episodes. Both 'stress' induced and spontaneous acid reflux episodes would be more likely in the presence of a low LOS pressure and so tend to increase with increasing severity of oesophagitis (and presumably decreasing LOS pressure). Acid reflux episodes after oesophageal motor contractions also occur and again were more common in patients than in control subjects.

This study has shown some of the important precipitating pressure events of acid reflux episodes in patients with gastro-oesophageal reflux disease under ambulant conditions. The prime importance of the LOS in preventing acid reflux has been confirmed. Further work is needed to determine the effects of therapeutic treatments on the precipitating mechanisms of acid reflux under ambulant conditions.

1 Kahrilas PJ, Dodds WJ, Hogan WJ, Kern DM, Arndorfer RC, Reece A. Esophageal peristaltic dysfunction in peptic RC, Reece A. Esophageal peristaltic dysfunction

2 Ahtaridis G, Snape WJ, Cohen S. Clinical and manometric findings in benign peptic strictures of the esophagus. Dig Dis Sci 1979; 24: 858-61.

3 Dent J, Dodds WJ, Friedman RH, Sekiguchi T, Hogan WJ Arndorfer RC, et al. Mechanisms of gastroesophagea reflux in recumbent asymptomatic human subjects. $\mathcal{F}$ Clin Invest 1980; 65: 256-67.

4 Dent J, Holloway RH, Toouli J, Dodds WJ. Mechanisms of lower oesophageal sphincter incompetence in patients with symptomatic gastro-oesophageal reflux. Gut 1988; 29: $1020-8$.

5 Wyman JB, Dent J, Dodds WJ, Toouli J, Downton J. Control of belching by the lower oesophageal sphincter. Gut 1990; 31: 639-46.

6 Janish HD, Weihrauch TR, Hempel KE. Is abdominal compression a useful stimulation test for analysis of lower oesophageal function? Dig Dis Sci 1984; 29: 689-95.

7 Holloway RH, Hongo M, Berger K, McCallum RW Gastric distension: a mechanism for postprandial gastroesophageal reflux. Gastroenterology 1985; 89: 779-84.

8 Savary M, Miller G. The esophagus: handbook and atlas of endoscopy. Solothurn, Switzerland: Gassmann, 1977.

9 Barham CP, Gotley DC, Miller R, Mills A, Alderson D. Ambulatory measurement of oesophageal function: clinical use of a new $\mathrm{pH}$ and motility recording system. $\mathrm{Br} \mathcal{F}$ Surg 1992; 79: 1056-60.

10 Barham CP, Gotley DC, Miller R, Mills A, Alderson D. Pressure events surrounding oesophageal acid reflux episodes and acid clearance in ambulant healthy volunepisodes and acid clearance

11 Gotley DC, Barham CP, Miller R, Arnold R, Alderson D. The sphinctometer: a new device for measurement of lower oesophageal sphincter function. Br $\mathcal{F}$ Surg 1991; 78 933-5.

12 Johnson LF, DeMeester TR. Twenty-four hour pH monitoring of the distal oesophagus: a quantitive measure of gastroesophageal reflux. Am $\mathcal{F}$ Gastroenterol 1974; 62 325-32.

13 Fink SM, McCallum RW. The role of prolonged oesophageal $\mathrm{pH}$ monitoring in the diagnosis of gastroesophageal reflux. $¥ A M A 1984 ; 252$ : $1160-4$.

14 Dodds WJ, Kahrilas PJ, Dent J, Hogan WJ, Kern MK, Arndorfer RC. Analysis of spontaneous gastroesophageal reflux and esophageal acid clearance in patients with reflux and esophageal acid clearance in patients with
reflux esophagitis. $\mathcal{F}$ Gastrointest Motil 1989; 1 : 105-14.

15 Dodds WJ, Dent J, Hogan WJ, Helm JF, Hauser R, Patel GK et al. Mechanisms of gastroesophageal reflux in patients with reflux esophagitis. $N$ Engl f Med 1982; 307: 1547-52.

16 Haddad JK. Relation of gastroesophageal reflux to yield sphincter pressures. Gastroenterology 1970; 58: 175-84.

17 Wyman JB, Dent J, Heddle R, Dodds WJ, Toouli J, Lewis I Belching: a clue to understanding of pathological gastroesophageal reflux? [Abstract]. Gastroenterology 1984; 88: 1303.

18 Patrikios J, Martin CJ, Dent J. Relationship of transient lower esophageal sphincter relaxation to postprandial gastroesophageal reflux and belching in dogs. Gastroenterology 1986; 90: 545-51.

19 Helm JF, Dodds WJ, Hogan WJ. Salivary response to esophageal acid in normal subjects and patients with reflux esophagitis. Gastroenterology 1987; 93: 1393-7. 